\title{
Editorial
}

\section{Chemistry that Impacts Us (and the Scientists Behind Them)}

\section{Guruswamy Kumaraswamy, Editor}

What is the most impactful chemistry ever elucidated? This is a contentious question, best suited for stirring late evening discussions at conferences. There are clearly many contenders. Depending on one's personal tastes, one could make a case for the greatest impact coming from developing a deeper understanding of molecular structure and bonding (G N Lewis, Linus Pauling) or for exquisite mastery over making chemical bonds (Bob Woodward, Bob Woodward), possibly for teaching us how to use new tools (Jack Roberts, Ahmed Zewail) or for teaching us about the molecules of life (G N Ramachandran, Venky Ramakrishnan). One could also consider those whose chemistry directly and immediately influenced people in a major way (Carl Djerassi, Fritz Haber). I am writing this editorial on the day the Chemistry Nobel was announced (Richard Henderson, Joachim Frank, and Jacques Dubochet for their work in the development of cryo-electron microscopy, with implications for understanding the structure of biological molecules). The alert reader would have noticed that half of the chemists I have cited here did not win the Nobel (GNL, BW, JR, GNR, CD) - but their work is indisputably Nobel-worthy. Bob Woodward, of course, did win a Nobel Prize, but one could argue that he deserved to win another. Therefore, I have listed him twice. The point I am trying to make is that while prizes and awards are important, perhaps we hype up their importance and occasionally forget that there are researchers who didn't win these awards but clearly did incredibly impactful work.

This issue features two scientists who did win the Nobel - Karl Ziegler and Giulio Natta. Karl Ziegler taught us how to make the carbon-carbon bonds that link ethylene units to form polyethylene. Creating carbon-carbon bonds in a novel, highly controlled manner has yielded many Nobel Prizes in Chemistry, including 
that to Karl Ziegler. Natta, on the other hand, was a structural chemist who understood the molecular structure of isotactic polypropylene and leveraged this knowledge to patent the polymerization of propylene to this wonderful polymer. The patents of Ziegler (on polyethylene) and Natta (on isotactic polypropylene) form the basis of today's staggeringly large polyolefin industry. About $70 \%$ of all polymers synthetically produced today are variants of polyethylene and polypropylene, and almost all of these are produced using advanced versions of the catalyst chemistry that was invented by Ziegler. The enormous importance of this chemistry was recognized immediately after its invention in the laboratory, and this process was scaled up and commercialized in the span of only a few years. Remarkably, commercial plants for polyethylene and polypropylene were set up before Ziegler and Natta received the Nobel. So, the story of this invention has everything - it has spectacular chemistry of carbon-carbon bond formation, it has beautiful structural stereochemistry, and it is the story of an amazing commercial success that continues to touch us every day, nearly 65 years after the first laboratory experiments.

The story of the invention of polyethylene and polypropylene is related by Prof. Swaminathan Sivaram who has a close personal connection to polyolefins. When a young Dr. Sivaram returned to India in the seventies, after a $\mathrm{PhD}$ with $\mathrm{H} \mathrm{C}$ Brown (who won the Nobel Prize for boron chemistry) and after postdoctoral training in anionic polymerization with Joe Kennedy, he joined an Indian Petrochemicals Corporation Limited (IPCL) that was in the process of setting up the first polypropylene plant in the country. As part of the initial IPCL team, Dr. Sivaram liaised extensively with the company that Natta was associated with (Montecatini Edison), and worked in the laboratory with Natta's students and postdocs, who had invented this technology. The beauty of this chemistry and its staggering importance had a lasting impact on Prof. Sivaram that continues to this day. When I was convincing Prof. Sivaram to pen these biographies, he told me about a pilgrimage he made to Bergamo, where Natta rests today. 
Prof. Sivaram's close connection to this chemistry and technology, and to the main players allows him to paint an intimate picture of the history, intrigues, disputes, and politics of polyolefins. The biographies are accompanied by two (slightly more) technical articles by scientists who are trying to reinvent the classical metal-catalyzed polymerizations to make them more relevant for the challenges of today. Samir Chikkali tells us about traditional Ziegler chemistry and also discusses where it fails. His article gives us glimpses into how researchers, including his group, are trying to address some of these failings. Kumar Vanka demonstrates how the growing power of computational approaches is finally giving us insights into the complex polyolefin chemistry at metal surfaces. The polyolefin chemistry of tomorrow might still be based on Ziegler's invention, but will need to incorporate new approaches, some of which might be designed in silico. 